\title{
Values in persons with borderline personality disorder: their relevance for the therapeutic interview
}

\author{
Milena Mancini, ${ }^{1}$ Giovanni Stanghellini ${ }^{1,2}$ \\ ${ }^{1}$ Department of Psychological, Health and Territorial Sciences, G. d'Annunzio University, Chieti, Italy; ${ }^{2}$ D. Portales University, Santiago, \\ Chile
}

\begin{abstract}
This is an explorative study on values of 25 patients affected by borderline personality disorder interviewed in a clinical setting (phenomenological-dynamic psychotherapy) and re-classified following Consensual Qualitative Research. We identified three main categories of values: recognition (the importance for attention, acknowledgment, commendation and acceptance by the other), authenticity (the importance of absolute emotional fusion with the other), and immediacy (the importance of instantaneous, hic et nunc satisfaction of one's needs/desires). Each of these values expresses a kind of 'logic', namely the logic of intimacy (the other's closeness as indispensable for defining oneself and establish/reinforce one's selfhood and identity), spontaneity (over-reliance on feelings unrestricted by social norms undermining their intensity), and instantaneity (glorification of 'now-moments'/execration of procrastination draining the vitality of feelings). The borderline person lives an emotional normativity constituted by the intensity of feelings under the spell of a frustrated normativity since they enter into a collision with the hypocrisy of common-sense ethical norms and social rules and conventions, as well as by potential conflicts with the feelings of the other. Acknowledging the values affirmed by borderline persons may help to better understand their condition - that is, to grasp 'what it is like' and make sense of the phenomena that affect them - and particularly to find a logic in their otherwise irrational and incomprehensible self-defeating behavior.
\end{abstract}

Key words: Authenticity; borderline personality disorder; immediacy; phenomenological-dynamic psychotherapy; recognition; values.

\section{Introduction}

\section{The therapeutic interview}

There is widespread recognition of the limitations of clinical interviews focused on easy-to-assess operationalizable symptoms in view of nosographical diagnosis (Kendler \& Parnas, 2008; Kendler \& Parnas, 2012; Kirk

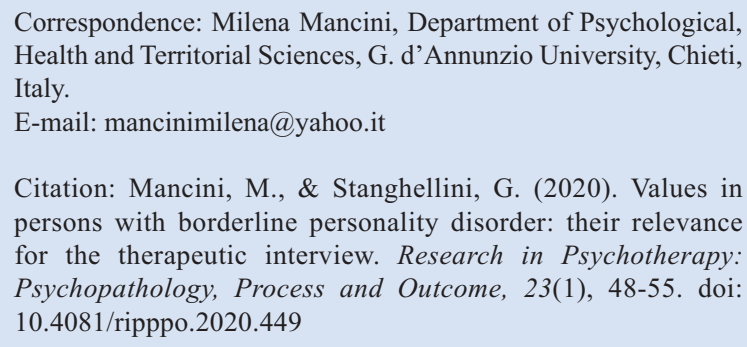

Received for publication: 22 January 2020.

Accepted for publication: 28 February 2020.

This work is licensed under a Creative Commons Attribution NonCommercial 4.0 License (CC BY-NC 4.0).

${ }^{\circ}$ Copyright: the Author(s), 2020

Licensee PAGEPress, Italy

Research in Psychotherapy:

Psychopathology, Process and Outcome 2020; 23:48-55

doi:10.4081/ripppo.2020.449
\& Kutchins, 1992; Sadler, Hulgus, \& Agich, 1994; Richardson, 1996; Stanghellini, 2004)- a practice obviously based on the clinician's values of objectivity and reliability (Spitzer, 2001). This approach downplays subtle anomalies of the patients' experience, regarding them as unreliable, difficult to assess, and unscientific. There are several undesirable consequences of this. The thinness of phenotypes and simplification of clinical constructs is the most apparent. Much of the complexity of living with mental disorders - the manifold of phenomena experienced by patients in all of their concrete and distinctive features - remains unexplored. Also, symptom-focused interviews discourage real dialogue, frustrates the patient's desire to be recognized, and reiterate asymmetry since they affirm the clinician's values, and ignore those of the patient. Another damaging consequence is the uncoupling of diagnostic and therapeutic procedures. Symptom assessment and understanding the patient come apart. Symptoms are reduced to indexes for diagnosis (Stanghellini, 2013).

From the vantage of the "therapeutic interview" (Stanghellini \& Mancini, 2017) - a dialogical method based on the phenomenological-dynamic approach (Stanghellini, 2016a; Stanghellini, 2019) - symptoms (and abnormal phenomena in general) present the opportunity for an encounter between the person and her vulnerability. In this perspective, symptoms are meaningful phenomena through which the hidden, yet operative (and perplexing, or disturbing) dimension of the patient's ex- 
istence is made manifest (Stanghellini, 2016b). Symptoms offer the prospect of establishing a new kind of meaningfulness in a person's existence. The symptom is an anomaly, but not an abnormal, aberrant or insane phenomenon in a strict sense. Rather, it is a salience that attracts someone's attention and awakens one's care for oneself. The symptom offers a vantage from which one can see oneself from another, often radically different and new, perspective (Stanghellini, 2013) since it reflects and reveals one's own vulnerability. As such, it is the contingent opportunity of a possible encounter between the person and her vulnerability. In this perspective, the symptom is not an accident to that person; rather it displays her/his true essence. Symptoms are the via regia to self-recognition: a person's vulnus displays what is most personal and intimate to her/his (Stanghellini, 2016a).

\section{The relevance of values in the therapeutic interview}

The therapeutic interview is much more than assessing operationalized symptoms. Rather, it is a quest for meaning and recognition. It seeks for order within and throughout the patient's life-world, that is the structure of her experiences and actions, stemming from her values. This paper explores the values of people with a borderline personality disorder as a key-feature of their life-world. The therapeutic interview is in touch with values-based practice (Fulford, 1989) which argues that it is essential to acknowledge the patient's values in linking up the sciences of medical and psychological care effectively with the unique individuals who are at the heart of the clinical encounter.

It is important in developing an in-depth awareness of the patient's values not to conflate them with abnormal beliefs since confusing idiosyncratic values with abnormal beliefs is not only conceptually wrong and ethically inadmissible, it is also therapeutically ineffective. Values are not symptoms to be 'killed'. They need to be acknowledged by the clinician as an integral part of the patient's form of life, and then modulated, accommodated with the requirements of reality, not eradicated.

An operationalized definition of 'value' is missing, yet a working definition is the following: values are all that matters to a given person (Fulford, 1989). Based on emotional experience, they are attitudes that regulate meaning-bestowing and the significant actions of the person, being organized into concepts that do not arise from rational activity but rather within the sphere of feeling (Scheler, 1973). Thus, grasping the values of a person is a key to understanding her way of interpreting her experience and representing herself. In general, values are keys to understanding a given form of life, since they contribute to establishing the "pragmatic motive" and the "system of relevance" that determine the meaning structure of the world a person lives in, and which regulate her style of experience and action (Stanghellini \& Mancini, 2017; Figure 1). Understanding a person means understanding the explicit or implicit motivations that make her/his behave in a given way. This is particularly relevant when awkward and at face value incomprehensible conduct (e.g. impulsive, self-destructive, or self-defeating behaviours) are at play, as it is the case with borderline persons.

\section{Materials}

This is a qualitative exploratory study on values in a group of 25 patients affected by borderline personality disorder performed in the period between 2016 and 2018 by one of the authors (M.M.). Diagnoses were assigned according to DSM-5 criteria. Disagreement among the two investigators about the diagnosis was a case of exclusion. Patients with substance abuse, severe head injury,

A)

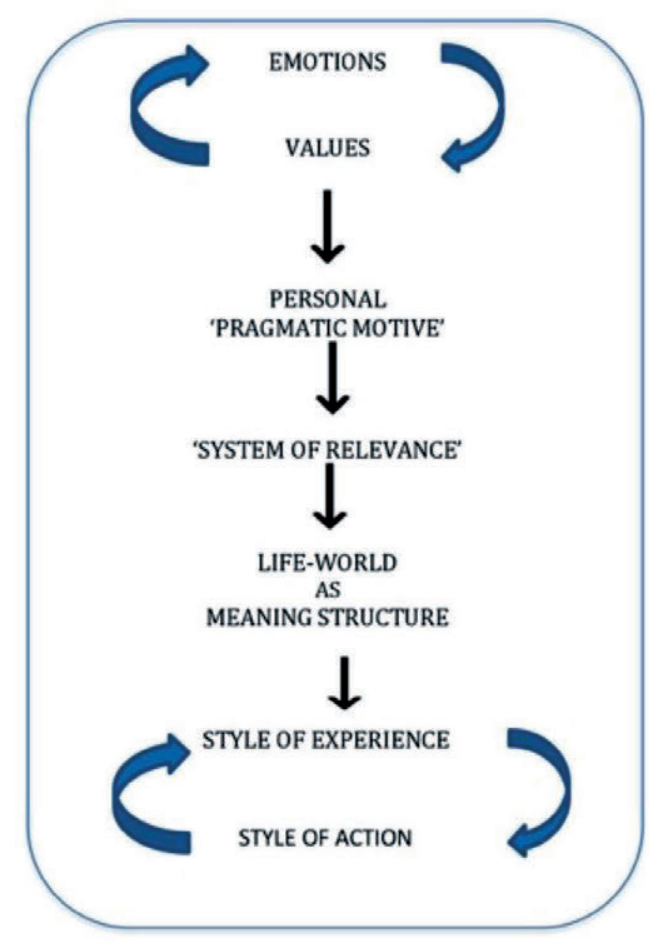

B)

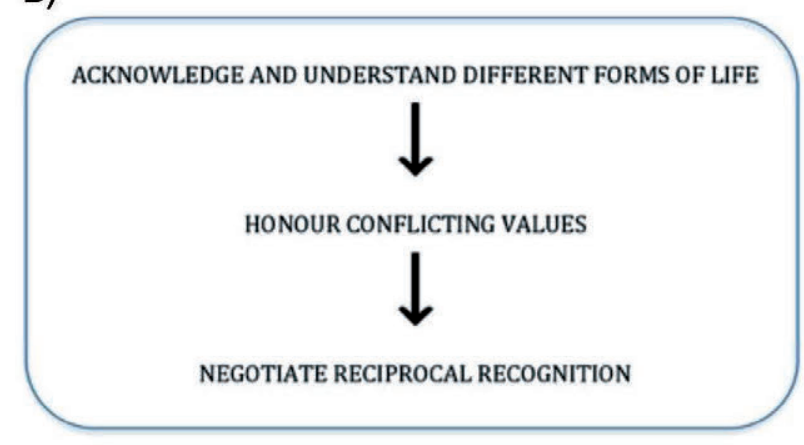

Figure 1. A) Steps to the genesis of the life-world and B) aims of the therapeutic interview. 
medical illness, neurological diseases and mental retardation were also excluded. Of the original 25 patients, $84 \%$ $(\mathrm{N}=21)$ were retained for subsequent qualitative analysis. The demographic features of the final sample are shown in Table 1.

\section{Methods}

The patients were under the interviewer's care. Patients were interviewed in a clinical setting (Phenomenological-Dynamic psychotherapy according to the PHD method (Stanghellini 2016a; Stanghellini \& Mancini, 2017), a kind of psychotherapy intended to enhance the patient's insight into her abnormal experiences and in general into the main features of their life-world. The duration of each interview was approximately 45 minutes. Each patient had been in psychotherapy for at least one year. Appropriate consent was obtained from all patients for the purpose of the interviews. The interviewer adopted an interactive conversational style exploring the life-world of patients, in particular their value-system. The working definition of 'value' was the following: all that matters to the persons and the ethos of the person that may implicitly or explicitly motivate her actions (Fulford, 1989; Fulford et al, 2012).

Interview questions related to values and other features of the patients' personal experience were not established in advance but were always generated within the interview context and attuned with the interviewee's personal experience and involvement. Values were re-classified following Consensual Qualitative Research (CQR), a consolidated method for qualitative research.

Diagnoses were established according to DSM-5 criteria on the basis of clinical evidence gathered during the interviews by M.M. and later discussed with G.S. In no case, there was a disagreement about diagnosis between the two researchers.

\section{CQR method}

Consensual Qualitative Research (CQR) method is an inductive method that is characterized by open-ended interview questions, semi-structured data collection techniques, in-depth examination of individual experiences, context-sensitivity and adoption of several judges throughout the data analysis process to foster multiple perspectives. It is a qualitative method that is concerned with bringing forth the typical feature(s) of subjective experiences in a given phenomenon (Stanghellini \& Ballerini, 2008). CQR based on the assumption that the consensus among the judges improves the decision-making quality and the accuracy or credibility of the results (Schielke, Fishman, Osatuke, \& Stiles, 2009). It is essential to obtain multiple perspectives from a team of expert researchers and to reach consensus through discussions regarding each researcher's interpretation of the data.
Such integration of multiple viewpoints through consensus is especially suited to research that requires rich descriptions of inner experiences. In particular, CQR is ideal for conducting in-depth studies of the experiences of individuals, especially of infrequent events or complex phenomena, to explore new areas or build a theory, and to study phenomena whose evaluation measures have not previously been designed (Hill, 2011; Hill et al., 2005). In the present study, data analysis was conducted by a senior psychiatrist (G.S.), and expert psychologist (M.M.) on the subjective experiences collected by interviews. These phenomena were digitized and organized in a phenomenological clinical record by the interviewer (M.M.). The external auditor was a senior psychiatrist (M.B.). Before and after such a process, we discussed our biases (mainly our personal prejudices about values and their relevance in the assessment and therapeutic process) regarding the potential results of the study, in order to limit the effects of such biases on the analyses of the data. Rotating teams of two judges (M.M. plus M.B., M.M. plus G.S. and G.S. plus M.B.) independently synthesized the raw data into 'core ideas' in order to reveal the essence of what has been reported by the patients. This was done (according to the principles of the CQR method: establishing objectivity via intersubjective agreement) by means of discussion between the Authors of this paper and the external auditor. The auditor gave his feedback individually to the primary team, which incorporated the appropriate changes, when necessary. During 'Cross-Analysis', we identified common themes (macro-categories) reflecting the experiences of participants. Within the macro-category 'Values in persons with the borderline disorder' we identified more specific themes called Categories (e.g., 'Authenticity'). According to the CQR method a typical Category must include more than half of the participants (Hill, Thompson, \& Williams, 1997). Finally, we asked for feedback from the auditors in order to make sure that the cross-analysis was clear and made sense

Table 1. Socio-demographic features of the study sample.

\begin{tabular}{lc}
\hline & $\begin{array}{c}\text { Participants } \\
\text { Persons with borderline disorder }\end{array}$ \\
\hline N. & 21 \\
\hline Gender & \\
$\begin{array}{l}\text { Male/Female } \\
\% \text { Male }\end{array}$ & $1 / 20$ \\
\hline Age & $4,76 \%$ \\
$<19$ & 0 \\
$20-30$ & $57,14 \%$ \\
$31-41$ & $42,86 \%$ \\
\hline Means (Age) & 31,05 \\
\hline SD & 4,82 \\
\hline
\end{tabular}




\section{Results}

Information on their values has been reported by each patient. We identified three main categories of values, namely i) Recognition, ii) Authenticity, and iii) Immediacy (Table 2).

\section{i) Recognition}

Twenty out of 21 responding patients reported at least one sentence related to this category. Description: The value of recognition expresses the importance of attention, acknowledgment, commendation and acceptance by the other which is indispensable for defining oneself and establish/reinforce one's selfhood and identity.

Core: Visceral need of belonging, being accepted and loved. Affirmation of the logic of intimacy.

The kind of teleology at play in all human relationships is the desire for reciprocal recognition.

We desire to be recognized by the other to such a degree that our being-so is acknowledged by the other as a value in itself. Our deepest need and desire is to be loved as we are, notwithstanding our limitations, weaknesses, faults, and culpabilities. We need the recognition of a 'You' to become and remain an 'I'.

In the borderline form of life, the value of recognition is directed to achieve apparently standard goals $e . g$. to belong, to be accepted, to draw close and enjoyably reciprocate with another, to exchange sentiments, ideas, secrets. These goals are felt by borderline persons as standard, basic aspirations of what we may call 'intimacy'. Since borderline persons are not capable of autonomy in the sense of establishing a coherent enough representation of themselves and remaining faithful to it (I need to belong to him, to laugh and cry with him. This makes me feel a person), they require the other to be present and loyal as a source of validation. Need for recognition is the underside of fear of abandonment that forces the borderline person to aspire - constantly and insatiably - to a sort of emotional osmosis with the other. The other is needed as a source of recognition (I would like to be beautiful for F., but he looks at other women... I feel invisible to him.... I get smaller and smaller!). The absence of the other makes the presence of the Self impossible. The other's absence, or incomplete presence, is often the reason for feelings of un-recognition and desperate loss of selfhood (If A. goes away, I don't not exist! I'm dead. I'm nobody!). The absent other, or the other who does not donate his entire self, is an abandoning other and an inauthentic other.

\section{ii) Authenticity}

Eighteen out of 21 responding patients reported at least one sentence related to this category.

Description: The value of authenticity expresses the importance of a kind of absolute emotional fusion with the other. To accomplish this value standard social conventions must be transgressed.

Table 2. Values in borderline persons: categories and core phenomena.

\begin{tabular}{lll}
\hline CATEGORY & CORE PHENOMENON & TYPICAL SENTENCES \\
\hline $\begin{array}{l}\text { 1. Recognition } \\
\mathbf{N}=\mathbf{2 0})\end{array}$ & $\begin{array}{l}\text { The importance of attention, acknowledgment, } \\
\text { commendation and acceptance by the other. } \\
\text { The closeness of the other is indispensable for defining } \\
\text { oneself and establish/reinforce one's selfhood and identity. }\end{array}$ & $\begin{array}{l}\text { If A. goes away, I don 't exist! I'm dead. } \\
\text { This makes me feel a person. }\end{array}$ \\
& $\begin{array}{l}\text { Core: } \\
\text { Visceral need of belonging, being accepted and loved. } \\
\text { Affirmation of the logic of intimacy }\end{array}$ & I would like to be beautiful for F., but he looks at other \\
& women ... I feel invisible to him... I get smaller and smaller!
\end{tabular}

\begin{tabular}{ll}
\hline 2. Authenticity & The importance of a kind of absolute emotional fusion \\
with the other. Standard social conventions must be \\
transgressed. \\
Feelings are \\
Core: \\
Execration of socially shared rules and roles as restrictions \\
to being oneselfAffirmation of the logic of spontaneity \\
- over-reliance on feelings. \\
worth taking this risk. Without emotions, I would be simply \\
dead. \\
The importance of instantaneous, hic et nunc satisfaction \\
of one's needs/desires. Distance and procrastination are \\
intolerable. \\
He's never there! Always busy with his "duties" as he calls \\
Core: \\
Visceral need for intensity. \\
Affirmation of the logic of instantaneity.
\end{tabular}

You [the therapist] say I'm his mistress! That word doesn't mean anything to me. I just love him - period! everything. I get pissed off by your roles and rules!

All that counts in life are emotions. Nothing else. Only emotions keep me alive. I know they can destroy me, but it's

If I text him, it means it's urgent! I have to ask him something! But he does not answer!

hem! I feel empty without him. I spend my days crying.. He absolutely has to move in with me!

There are only 'now's'. The word 'tomorrow'means nothing to me. 
Core: Execration of socially shared rules and roles as restrictions to being oneself. Affirmation of the logic of spontaneity - over-reliance on feelings.

The values by which the borderline person is driven are not the ethical norms or social conventions that structure and organize our common-sense interpersonal world. Rather, they refuse such conditions that they consider expressions of the hypocrisy of the pallid emotions by which other persons live (You [the therapist] say I'm his mistress! That word doesn't mean anything to me. I just love him-period!). The affirmation of authenticity entails the affirmation of the logic of spontaneity, that is the over-reliance on feelings (All that counts in life are emotions. Nothing else. Only emotions keep me alive. I know they can destroy me, but it's worth taking this risk. Without emotions I would be simply dead). The borderline person's normativity is an emotional normativity constituted by the intensity of emotional values which are nevertheless constantly frustrated by the ethical norms and the social rules and conventions that structure our shared interpersonal world (Feelings are everything. I get pissed off by your roles and rules!). Borderline person cannot - or will not - let their bouts of energy be restricted by or conformed to the needs of other people, ethical norms, or social conventions, all of which they considers inauthentic and therefore as an unwarranted challenge to their truly natural being, their spontaneity. Feelings are the principal value for the borderline person. Norms are inauthentic because they disregard the intimate feelings of the person whose behaviour they are meant to inform and orient.

\section{iii) Immediacy}

Fourteen out of 21 responding patients report at least one sentence related to this category.

Description: The value of immediacy expresses the importance of instantaneous, hic et nunc enjoyment or satisfaction. Distance and procrastination are intolerable.

Core: Visceral need for intensity. Affirmation of the logic of instantaneity.

Borderline persons are almost incapable to distance themselves from their own desires/needs/emotions and of appropriating these in the light of the norms that are part of being a person in a world shared with other persons (There are only 'now's'. The word 'tomorrow' means nothing to me). Thus they are condemned to simply live the intense but disrupted life of their feelings (If I text him, it means it's urgent! I have to ask him something! But he does not answer!). The affirmation of immediacy entails the rejection of norms (ethical as well as social) that allow us to distance ourselves from the immediate satisfaction of our desires/needs/emotions in the light of our care for living with other people, but that somehow undermine by the intensity of these feelings. Norms and conventions are merely viewed as annoying attempts to drain the vitality that sustains the borderline's form of life. The frustration of enjoyment continuously generates desperate attempts to maintain one's vitality in the face of what are considered to be the encumbering strictures and platitudes of everyday life (He's never there! Always busy with his "duties" as he calls them! And I feel empty without him. I spend my days crying).

\section{Discussion}

We will briefly discuss these findings and attempt to draw a picture of the life-world inhabited by borderline persons in the light of the values affirmed by them. In the following, we will contrast the borderline persons' values with the main features of their life-world, namely their way of experiencing time, their own body and other persons.

\section{Lived time}

The way borderline persons experience time has been nicely encapsulated in the formula intra-festum (Kimura, 1992): Like in the atmosphere of the feast, in the intrafestum temporality, we find the irruption of spontaneity and ecstasy, oblivious of past and future. The intra-festum yet is also chaotic immediateness. The person is absorbed in an unmediated instantaneity - the pure or absolute 'now' devoid of all relation with anteriority and posteriority, i.e. with the past as the Self's retention of the bygone, and with the future as the Self's projection of the 'now' in the forthcoming. Here Kimura (1992), following Husserl, defines 'retention' as the past as intentionally contained in the present, and 'protention' as the future as anticipated in the present, so that when both retention and protention are functioning the present moment keeps in view past and future. This is not the case with the intrafestum where the 'now' is pure now-moment (presentification), lacking protection and retention. Giving themselves independently from past and future, borderline persons cannot measure the length of these now's, as one could do with a present which develops out of the past and toward the future. Thus, the absolute 'now' of the intra-festum is without any relation with a Self as a narrative Self (Stanghellini \& Rosfort, 2013a). This idea is quite congruent with the hypothesis that identity disturbance - that is, the difficulty in maintaining a stable sense of self through time - is one of the defining features of borderline personality disorder (e.g. Kernberg, 1984; Westen \& Cohen, 1993). Temporal fragmentation may help in understanding the kind of disorder of selfhood and identity that affects borderline persons.

Meares (2012) interprets the splitting of the borderline's Self as a kind of temporal splitting and Fuchs (2007) suggests that the increasing prevalence of this condition may, at least in part, be related to the fragmentation of temporality in post-modern society - acceleration of momentary events, mobility of work-life, futility of communication, 
fragility of relationships, receding loyalty and commitment - which overlap with the borderline person's logic of instantaneity. The affirmation of the value of immediacy may help borderline persons to avoid the difficulty of tolerating the threatening ambiguity of interpersonal relationships and the uncertainty of the future. Its price, however, may consist in reinforcing a fragmented existence. The outcome of this glorification of the present moment is the non-integration of past and future into the present - that as a consequence of this may lack 'breadth' and profundity - causing a chronic feeling of inner emptiness and the lack of a coherent sense of identity.

\section{Lived body}

The body as experienced by borderline persons can be described as the headquarters of a destructive as well as exhilarating power. It is felt like the source of untamed energy, deformed by a plurality of invisible forces that take the representation of oneself to pieces, reducing it to a mere accumulation of disordered emotions and drives. Yet it is also felt the center of a vital power that expresses a boosting vitality, seducingly in touch with invigorating sensations. It is an intensive body, expressing an irrepressible and wild vitality, a brutal vitality entirely at the mercy of the basic biological values, a crude unmediated bodily vitality that does not accommodate to pre-reflective intentional structures or to reflective cognitive efforts (Stanghellini \& Mancini, 2017; Stanghellini, 2016a; Stanghellini, 2018; Stanghellini, 2020; Schmidt, in press).

Borderline persons may feel in their flesh the presence of spontaneous energy without any clear direction or definite target. It is emotional energy that throws itself at the other with an overwhelming intensity. These feelings parallel very well with the borderline person's affirmation of the logic of spontaneity and in general with the value of authenticity and the execration of all clichés and secular moral imperatives. As it is the case with their intra-festum temporality and the absorption in immediateness, borderline persons seem to make a virtue out of necessity (de necessitate virtutem): the affirmation of spontaneity and the overreliance on feelings are the deliberate glorification of their chaotic body, and the decision to vibrate at one with their sheer flesh, immediately felt without the intercession of a representation, a story, language, or thought.

\section{Other persons}

To borderline persons, the other is a hoped-for source of selfhood through recognition. The value of recognition is tightly intertwined with the main dimensions of borderline psychopathology, including the instability of the feeling of one's own Self (e.g. Rossi Monti \& D'Agostino, 2019), the fragility of acknowledging oneself as a responsible agent (e.g. Gunderson \& Lyons-Ruth, 2008) and the difficulty in constructing a coherent narrative about one's own deeds (e.g. Meares, 2012).
From these vulnerabilities stems the agonistic character of recognition in the interpersonal world of borderline persons: recognition is a task, a desperately searched-for goal, not datum or a matter of fact, and this may imply a conflictual relationship with the other. Since self-recognition inevitably needs the help of the other (Ricoeur, 2005), the need for recognition forces the borderline person to aspire, constantly and insatiably, to a sort of emotional osmosis with the other (Stanghellini \& Rosfort, 2013a). Thus the values at play in the interpersonal world of borderline persons are directed to achieve a sense of being a person through the feeling of belonging, the reciprocation of sensuous experiences, as well as the experience of being forgiven and consoled. These needs and expectations reflect the logic of intimacy. Yet, as we have seen in the preceding paragraphs, the other is a partner with whom also spontaneity and instantaneity are expected. All this may be at the root of the borderline person's frustration, feeling of emptiness and despair, since the values at play in the interpersonal world of borderline persons are not only difficult to attain but potentially in conflict with one another.

\section{Conclusions}

\section{Limitations and directions for future research}

A comprehensive assessment of the borderline condition should embrace, next to symptoms, abnormal experiences and behaviors, mental functioning including defense mechanisms, etc., also the values at play in the borderline life-world. Acknowledging the values affirmed by borderline persons may help to better understand their condition - that is, to grasp 'what it is like' and make sense of the phenomena that affect them - and particularly to find a logic in their otherwise irrational and incomprehensible self-defeating behavior.

In this qualitative exploratory study on values in a group of patients affected by borderline personality disorder, interviewed in a clinical setting (phenomenological-dynamic psychotherapy) we identified three main categories of values in these patients, namely recognition (the importance for attention, acknowledgment, commendation and acceptance by the other), authenticity (the importance of absolute emotional fusion with the other), and immediacy (the importance of instantaneous, hic et nunc satisfaction of one's needs/desires). What is relevant is that these phenomena are positively affirmed as values by borderline persons, and not simply passively suffered as irrational needs. Rather, each of these values expresses a kind of 'logic', namely the logic of intimacy, spontaneity, and instantaneity.

The recognition of their values is an essential prerequisite for establishing an effective therapeutic relationship. It is especially useful in clinical practice 'to recognize the value of recognition' for borderline persons in order to 
promote successful therapies. Traumatic situations for these patients typically originate in the context of selfother relationships characterized by feelings of non-recognition. Borderline persons need the other to be a source of recognition and validation and this need is often frustrated. The other's recognition is fundamental not only to their self-esteem but also to their sense of being a self: self-coherence and self-identity over time depend on the other's recognition. The therapeutic relationship is an occasion to heal this "invalidating trauma" (Meares, 2000) centered on experiences of non-recognition provided that the therapeutic process is embedded in a special kind of emotional atmosphere or intimate conversation during which the patients' values (recognition, authenticity and immediateness) are acknowledged rather than treated as symptoms.

A good diagnosis should reflect the clinical complexity of the borderline condition and promote the integration of a nomothetic understanding and the idiographic knowledge of the patient, which is essential for individual case formulation and effective treatment planning. It is not difficult to perceive some common ground between this phenomenology-based values and person-centered approach and the theoretical-clinical framework of the Psychodynamic Diagnostic Manual (PDM-2; Lingiardi \& McWilliams, 2017) as both approaches emphasize the relevance of the patients' subjective experience (Lingiardi \& McWilliams, 2018).

At a glance, we may notice that borderline persons live under the spell of what we may call a "frustrated normativity" (Stanghellini \& Rosfort, 2013a; Stanghellini \& Rosfort, 2013b). The norms by which the borderline person is driven are not the ethical norms or social conventions that structure and organize our interpersonal world. Rather, borderline persons refuse such conditions, thus entering into collision with what they consider the hypocrisy and the inauthenticity of the pallid emotions by which all the other persons live.

The borderline person's normativity is an 'emotional normativity' constituted by the intensity of feelings which are nevertheless constantly frustrated by common-sense ethical norms and social rules and conventions, as well as by potential conflicts with the feelings of the other. Borderline persons cannot - or will not - let themselves be restricted by social conventions, which they consider inauthentic and therefore as an unwarranted challenge to the logic of intimacy, spontaneity, and instantaneity.

The main limitation of this study is the small number of patients. Also, further limitations include that we did not use a standard interview to establish the diagnosis and an $a d$ hoc interview to assess values and other dimensions of the borderline life-world are missing. Directions for future research should include: expanding this study via the assessment of a larger sample of patients and devising an ad hoc structured interview to assess values in borderline persons and in other psychopathological conditions; look- ing for meaningful relations in borderline persons between values and emotions, especially dysphoria, anger and shame; deepening our knowledge about the overall structures of the life-world borderline persons live in, namely their experience of lived time, space, body and others, and the meaningful relations of these with values; assessing the relevance of these findings for the development of effective psychotherapeutic care of borderline persons, especially from a phenomenological-dynamic perspective.

\section{References}

Fuchs, T. (2007). Fragmented selves: Temporality and identity in borderline personality disorder. Psychopathol 40(6), 379387.

Fulford, K. W. M. (1989). Moral theory and medical practice. Cambridge: Cambridge University Press.

Fulford, K. W. M., Peile, E., \& Carroll, H. (2012). Essential values-based practice: clinical stories linking science with people. Cambridge University Press.

Gunderson, J. G., \& Lyons-Ruth, K. (2008). BPD's interpersonal hypersensitivity phenotype: A gene-environment-developmental model. J Personality Disord 22(1), 22-41.

Hill, C. E. (2011).Consensual qualitative research: A practical resource for investigating social science phenomena. Washington, DC: American Psychological Association.

Hill, C. E., Knox, S., Thompson, B. J., Williams, E. N., Hess, S. A., \& Ladany, N. (2005). Consensual qualitative research: An update.J Counseling Psychol 52(2), 196.

Hill, C. E., Thompson, B. J., \& Williams, E. N. (1997). A guide to conducting consensual qualitative research. The Counseling Psychologist 25(4), 517-572.

Kendler, K. S. \& Parnas (2012). Philosophical Issues in Psychiatry II: Nosology. Oxford University Press.

Kendler, K. S. \& Parnas. J. (eds.) (2008). Philosophical Issues in Psychiatry: Explanation, Phenomenology, and Nosology. Baltimore, MD: Johns Hopkins University Press.

Kernberg, O. (1984). Severe personality disorders. New Haven: Yale University Press.

Kimura, B. (1992). Ecrits de psychopathologie phénoménologique. Paris: Presses Universitaires de France.

Kirk, S. A., Kutchins, H. (1992). The Selling of the DSM: The Rhetoric of Science in Psychiatry. New York: Aldine de Gruyter.

Lingiardi, V., \& McWilliams, N. (2018). Introduction to the special issue on the Psychodynamic Diagnostic Manual, (PDM2): The PDM: Yesterday, today, tomorrow. Psychoanal Psychol 35(3), 289.

Lingiardi, V., \& McWilliams, N. (Eds.). (2017).Psychodynamic diagnostic manual: PDM-2. Guilford Publications.

Meares, R. (2000). Intimacy and alienation: Memory, trauma and personal being. Routledge.

Meares, R. (2012). A dissociation model of borderline personality disorder. New York, NY: Norton \& Company.

Richardson, J. T. (Ed.) (1996). Handbook of Qualitative Research Methods for Psychology and the Social Sciences. Leicester: British Psychological Society.

Ricoeur, P. (2005). The Course of Recognition. Harvard: Harvard University Press.

Rossi Monti, M. \& D’Agostino, A. (2019). Dysphoria in bor- 
derline persons. In: Stanghellini G. et al. (eds.), The Oxford Handbook of Phenomenological Psychopathology (pp. 827838). Oxford: Oxford University Press.

Sadler, J. Z., Hulgus, Y. F., \& Agich, G. J. (1994). On values in recent American psychiatric classification. J Med Philosoph 19, 261-277.

Scheler, M. (1973). Formalism in ethics and non-formal ethics of values: A new attempt toward the foundation of an ethical personalism. Evanston: Northwestern University Press.

Schielke, H. J., Fishman, J. L., Osatuke, K., \& Stiles, W. B. (2009). Creative consensus on interpretations of qualitative data: The Ward method.Psychother Res 19(4-5), 558-565.

Schmidt, P. (in press). No Body? Disturbed Self-Experience in Borderline Personality Disorder. In: C. Tewes \& G. Stanghellini (eds.) Time and Body. Phenomenological and Psychopathological Approaches. Cambridge: Cambridge University Press.

Spitzer, R. L. (2001). Values and assumptions in the development of DSM-III-R: an insider's perspective and a belated response to Sadler, Hulgus, and Agich's "On values in recent American psychiatric classification.” J Nervous Mental Dis 189, 351-359.

Stanghellini, G. (2004). The puzzle of the psychiatric interview. J Phenomenological Psychol 35(2), 173-195.

Stanghellini, G. (2013). Philosophical Resources for the Psychiatric Interview. In The Oxford Handbook of Philosophy and Psychiatry (Edited by K.W.M. Fulford, Martin Davies, Richard G.T. Gipps, George Graham, John Z. Sadler, Giovanni Stanghellini, and Tim Thornton), Oxford/New York: Oxford University Press; pp. 321-356).

Stanghellini, G. (2016a). Lost in Dialogue: Anthropology, Psy- chopathology, and Care. Oxford/New York: Oxford University Press.

Stanghellini, G. (2016b). Phenomenological Psychopathology and Care. From Person-Centered Dialectical Psychopathology to the PHD Method for Psychotherapy. In: G. Stanghellini \& M. Aragona (eds.) An Experiential Approach to Psychopathology (pp. 361-378). Cham: Springer.

Stanghellini, G. (2018). L'amore che cura. La medicina, la vita e il sapere dell'ombra. Milano: Feltrinelli.

Stanghellini, G. (2019). The PHD Method for Psychotherapy: Integrating Phenomenology, Hermeneutics, and Psychodynamics. Psychopathol 52(2), 75-84.

Stanghellini, G. (2020). Selfie. Sentirsi nello sguardo dell'altro. Milano: Feltrinelli.

Stanghellini, G., \& Ballerini, M. (2008). Qualitative analysis. Its use in psychopathological research. Acta Psychiatrica Scandinavica 117(3), 161-163.

Stanghellini, G., \& Mancini, M. (2017). The therapeutic interview in mental health: A values-based and person-centered approach. Cambridge: Cambridge University Press.

Stanghellini, G., \& Rosfort, R. (2013a). Emotions and personhood: exploring fragility-making sense of vulnerability. Oxford/New York: Oxford University Press.

Stanghellini, G., \& Rosfort, R. (2013b). Borderline Depression A Desperate Vitality. J Consciousness Studies 20(7-8), 153177.

Westen, D. \& Cohen, R.P. (1993). The self in Borderline Personality Disorder: A psychodynamic perspective. In: Z.V Segal \& S.J. Blatt (eds) The self in emotional distress: cognitive and psychodynamic perspectives. New York: Guildford Press. 